\title{
Analisis Kinerja Mikro Turbin Gas Bahan Bakar LPG (Liquefied Petroleum Gas)
}

Youssuf Qardhawi ${ }^{1 *}$, Nurshofi Ghaffar ${ }^{1}$, Eko Prestyo ${ }^{1}$, Rudi Hermawan ${ }^{1}$, Erlanda Augupta Pane ${ }^{1}$

Fakultas Teknik Universitas Pancasila

Jl. Raya Lenteng Agung No.56-80 Srengseng Sawah 12640 Daerah Khusus Ibukota Jakarta

* gardhawi2603@gmail.com

DOI: https://doi.org/10.21107/rekayasa.v14i3.12230

\begin{abstract}
The Micro Gas Turbine is a device that functions to convert chemical energy from fuel from the combustion process into mechanical energy, which is then converted back to a generator to become electricity. This study aims to obtain the results of performance testing as well as the results of the comparison analysis of the Gas Turbine Micro from the design and testing of the assembly tool. The fuel used in this Gas Micro Turbine is LPG (Liquefied Petroleum Gas). The advantages of LPG are it is easy to obtain, has a high octane value so that the power generated is greater, has a high vapor pressure so there is no need to use a pump to drain it. The result of this research is that the addition of a fire source can increase the turbine inlet temperature although it is not significant because the fire does not burn continuously due to the compressor rotation being too forceful. In the first and second actual tool tests, the temperatures were $317.48 \mathrm{~K}$ and $323.75 \mathrm{~K}$, different from the results of the analysis on the ANSYS software where the temperature was $766 \mathrm{~K}$ and $793 \mathrm{~K}$.
\end{abstract}

Key words : renewable energy, thermodynamics, micro gas turbine, liquefied petroleum gas

\section{PENDAHULUAN}

Seiring dengan perkembangan zaman yang semakin maju, maka ilmu pengetahuan dan teknologi pun semakin berkembang dengan pesat. Kemajuan yang dihasilkan dapat terealisasikan dalam kehidupan kita karena adanya penguasaan ilmu pengetahuan dan teknlogi diberbagai bidang. Keterbatasan sumber energi dari fosil merupakan salah satu batu loncatan bagi manusia untuk dapat memanfaatkan sumber energi yang baru terbarukan agar tidak terjadinya krisis energi dimasa yang akan mendatang.

Berdasarkan data Badan Pusat Statistik (2019) Indonesia merupakan negara kepulauan yang luasnya kurang lebih $1.916 .906,77 \mathrm{~km}^{2}$. Luasnya negara Indonesia tidak dibarengi dengan meratanya kesejahteraan bagi masyarakatnya khususnya dalam segi kelistrikan. Berdasarkan data Potensi Desa (PODES) yang dikeluarkan oleh BPS tahun 2014, masih terdapat sekitar 2.500 desa di Indonesia yang sama sekali belum menikmati

\footnotetext{
Article History:

Received: June, 30 ${ }^{\text {th }}$ 2021; Accepted: November, 17 2021 Rekayasa ISSN: $2502-5325$ has been Accredited by Ristekdikti (Arjuna) Decree: No. 23/E/KPT/2019 August 8th, 2019 effective until 2023
}

akses tenaga listrik. Sebagian besar desa tersebut berada di wilayah Indonesia bagian timur, yaitu Provinsi Papua dan Papua Barat.

Pembangkit energi skala mikro merupakan salah satu teknologi renewable energy yang dapat dimanfaatkan oleh masyarakat. Pembangkit energi skala mikro banyak dibutuhkan terutama untuk kondisi lingkungan di daerah pedesaan, kantor, dan rumah tangga. Pembangkit energi skala mikro memiliki keunggulan yaitu kerapatan dayanya yang tinggi, dapat menggunakan bahan bakar baik bahan bakar cair ataupun bahan bakar gas, dampak terhadap lingkungan yang kecil, dan biaya operasi serta perawatan yang rendah

Mikro Turbin Gas (MTG) adalah mesin putar dengan poros tunggal yang mengekstraks energi dari aliran gas pada pembakaran mikro (Oppong, Spuy, and Diaby 2015). Mikro Turbin Gas ini umumnya terdapat komponen berupa kompresor, turbin dan generator yang hanya terhubung

\section{Cite this as:}

Qardhawi Y., Ghaffar, N., Prestyo, E., Hermawan, R \& Pane, E.A. (2021).Analisis Kinerja Mikro Turbin Gas Bahan Bakar LPG (Liquefied Petroleum Gas). Rekayasa 14 (3). 393-400. doi: https://doi.org/10.21107/rekayasa.v14i3.12230.

(c) 2021 Youssuf Qardhawi 
dengan satu shaft. Mikro Turbin diproduksi pertama kali oleh Kurt Schreckling dengan model FD3/67, Kemudian pada tahun 1936 digantikan oleh turbin aliran radial ke dalam berdasarkan paten oleh penemu Italia, Guido Zerkowitz (Patra n.d.). Kelebihan dari Mikro Turbin Gas dibandingkan dengan teknologi pembangkit listrik mikro yang lainnya adalah memiliki ukuran yang relatif tidak besar, operasi yang mudah dijalankan, serta memiliki variasi dalam hal bahan bakar (Nascimento, 2013) dan dapat diaplikasikan dengan bahan-bakar yang berbeda-beda, seperti solar, ethanol, LPG, biomass, compressed natural gas (CNG), biogas, dan sebagainya (Koo, 2015). Seperti pada Gambar 1 yang merupakan Mikro Turbin Gas yang dibuat oleh tim.

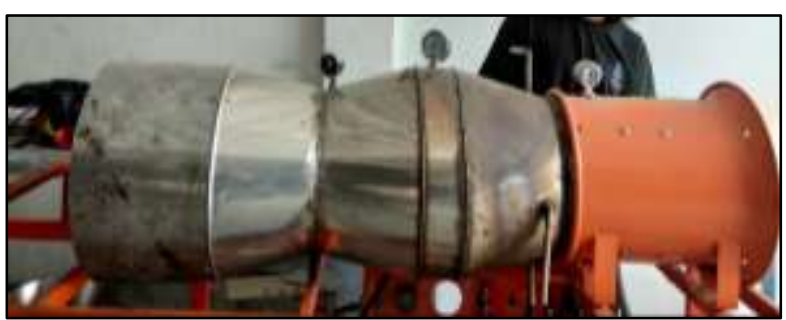

Gambar 1. Mikro Turbin Gas

Bahan bakar yang digunakan yaitu LPG. Liquefied Petroleum Gas (LPG) adalah bahan bakar gas yang terdiri dari campuran utama propan dan butan dengan sedikit tambahan hidrokarbon tidak jenuh (propilen dan butilen) dan beberapa fraksi $C_{2}$ yang lebih ringan dari $C_{5}$ yang lebih berat. Senyawa yang terdapat pada LPG adalah propan $\left(\mathrm{C}_{3} \mathrm{H}_{8}\right)$, propilen $\left(\mathrm{C}_{3} \mathrm{H}_{6}\right)$, normal dan iso-butan $\left(\mathrm{C}_{4} \mathrm{H}_{10}\right)$ dan butilen $\left(\mathrm{C}_{4} \mathrm{H}_{8}\right)$. LPG merupakan bahan bakar gas yang dicairkan dan memiliki berat jenis lebih besar daripada udara (Syukur 2011). LPG merupakan produk dari penyaringan minyak bumi yang berisi propane, beberapa propylene, butane, dan hydrocarbon. Propane adalah sebuah bahan bakar yang sering digunakan untuk jenis pembakaran dalam walaupun bisa menggunakan bensin dan diesel (Raslavicius). LPG mudah didapatkan dari mana saja karena dijual dimana saja. LPG mengandung $40 \%$ propane dan $60 \%$ butane dan juga mengandung hidrokarbon ringan lain dalam jumlah kecil, misalnya etana dan pentana (Pangestu, 2019). Cara kerja yang digunakan pada sistem mikro gas turbin didasarkan pada siklus Brayton (Kusnadi, 2016).

\section{METODE PENELITIAN}

Penelitian ini dilakukan pengambilan data di PT Defa Angkasa Utama. Tahap pertama yang dilakukan adalah dengan mengumpulkan berbagai referensi yang berkaitan dengan alat Mikro Turbin Gas. Setelah itu melakukan 2 kegiatan, yaitu pembuatan alat dan mengidentifikasi desain yang telah dibuat oleh perancang. Selanjutnya adalah pengujian kinerja dari alat Mikro Turbin Gas yang telah dibuat dan melakukan analisa simulasi dengan menggunakan software ANSYS. Software ANSYS memudahkan penggunanya agar dapat mensimulasikan skenario multi-fisika seperti struktur fluida. Setelah dilakukan pengujian dan simulasi dilakukan perbandingan hasil analisa dan uji alat tersebut.

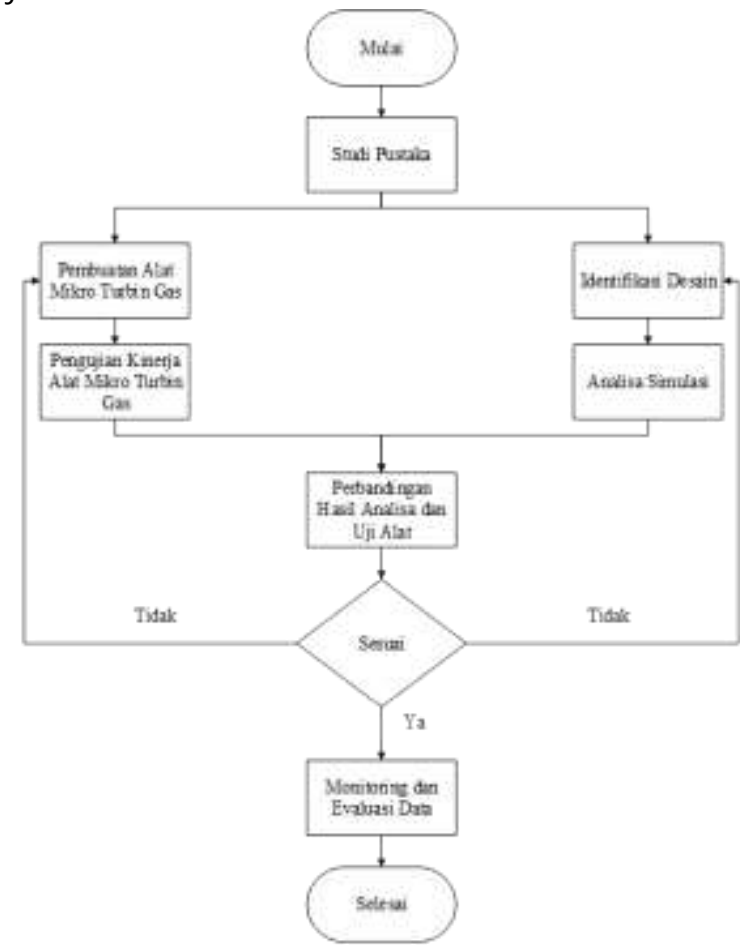

Gambar 2. Metode Penelitian

Pada modifikasi pertama yang dilakukan didapatkan hasil yang sesuai dengan siklus yang bekerja yaitu siklus brayton dimana suhu keluar turbin lebih besar dibandingkan dengan suhu masuk turbin. Setelah itu dilakukan simulasi menggunakan CFD. Pada Tahap Simulasi Analisis Menggunakan CFD akan menggunakan software Ansys Workbench. Tujuan simulasi untuk mengetahui fluida yang masuk mikro turbin gas. Pada software ini menggunakan Fluid Flow (Fluent) untuk melakukan simulasi. Langkah - langkah yang harus dilakukan pada Fluid Flow (Fluent) yaitu : 
- Geometry, Pengecekan geometri agar benda dapat terdeteksi dan tidak ada kesalahan pada benda yang sudah dibuat. Pada geometri pun berfungsi untuk membuat benda yang akan dilakukan untuk simulasi. Pada penelitian kali ini geometri akan dibentuk menjadi 2D ruang bakarnya. Pertama membuat bentuk geometri ruang bakar didalam ansys seperti dibawah ini dalam penelitian kali ini ruang bakar akan menggunakan $2 \mathrm{D}$.

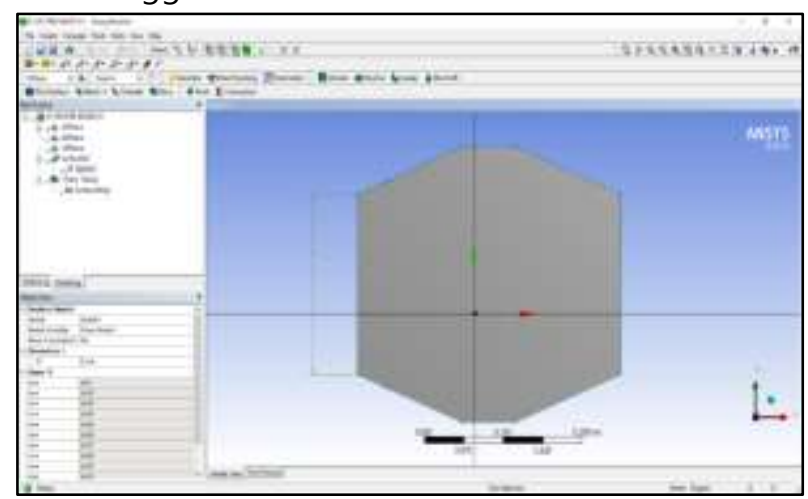

Gambar 3. Desain 2D Ruang Bakar dalam Geometri

- Mesh, Melakukan meshing yaitu pemberian grid dan pemilihan bagian - bagian seperti inlet, outlet, dan wall. Pada Penelitian ini ruang bakar memiliki 2 inlet yaitu untuk udara dan bahan bakar.

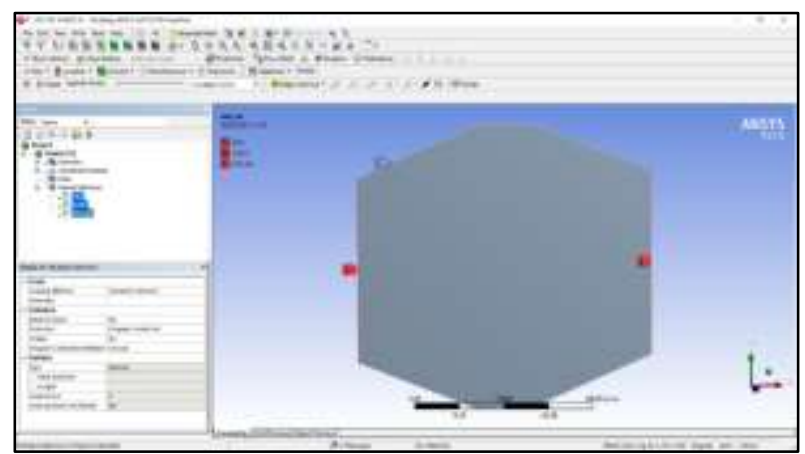

Gambar 4. Meshing

- Setup, Pada setup nilai inlet, outlet, wall, material yang digunakan akan diatur pada langkah ini. penentuan formulasi penyelesaian dan proses solusi numerik yang akan dilakukan. Setup kali ini akan menggunakan bahan bakar gas LPG. Pada model digunakan energy: on, viscous standard $k$ epsilon, dan menggunakan species transport.

Untuk mendapatkan hasil yang ideal maka diperlukannya perhitungan yang sangat tepat. Pada Mikro Turbin Gas ini digunakannya perhitungan termodinamika untuk mencari keidealan suatu temperatur, tekanan, entropi dan lain-lain. Berikut ini adalah contoh perhitungan yang digunakan pada Mikro Turbin Gas (Sitepu, 2014).

$$
\eta_{t}=\frac{\ln \left[1-\eta_{k}+\eta_{k}\left(\frac{P_{2}}{P_{1}}\right)^{\frac{k-1}{k}}\right]}{\left(\frac{k-1}{k}\right) \ln \left(\frac{P_{1}}{P_{2}}\right)}
$$

Dimana :

$\eta \mathrm{t}=$ efisiensi turbin (\%)

$\eta \mathrm{k}=$ efisiensi kompresor (\%)

$\mathrm{P}_{2}=$ Tekanan keluar kompresor (bar)

$\mathrm{P}_{1}=$ Tekanan masuk kompresor (bar)

Dimana :

$$
W_{K \text { aktual }}=\frac{W_{k}}{\eta_{k}}=\frac{h_{2}-h_{1}}{\eta_{k}}
$$

$\mathrm{h}_{2}=$ entalpi keluar kompresor $(\mathrm{kJ} / \mathrm{kg})$

$\mathrm{h}_{1}=$ entalpi masuk kompresor $(\mathrm{kJ} / \mathrm{kg})$

$$
W_{\text {turbin aktual }}=\eta_{t}\left(W_{\text {turbin ideal }}\right)
$$

Dimana :

$\mathrm{W}_{\text {turbin aktual }}=$ kerja turbin aktual $(\mathrm{kJ} / \mathrm{kg})$

$\mathrm{W}_{\text {turbin ideal }}=$ kerja turbin ideal $(\mathrm{kJ} / \mathrm{kg})$

Suhu gas aktual turbin :

$$
h_{4 a}=h_{3}-W_{T a}
$$

Panas aktual masuk ruang bakar

$$
q_{\text {in }}=\left(h_{3}-h_{2}\right)
$$

Pada penelitian ini menggunakan simulasi ANSYS dengan software fluid flow (fluent) dimana output dari simulasi kali ini akan menghasilkan nilai temperatur dari ruang bakar. Langkah - langkah yang digunakan yaitu menggunakan geometry, mesh, setup, dan result. Kali ini untuk pengaturan pada simulasi ANSYS kali ini akan menggunakan model digunakan energy: on, viscous standard $k$ epsilon, dan menggunakan species transport.

\section{HASIL DAN PEMBAHASAN}

Desain MTG sebelumnya pada Gambar 5 memiliki tambahan pada sistem kompresor turbocharger, namun spesifikasi turbocharger harus diperkecil kembali dikarenakan laju aliran bahan bakar dan laju aliran udara nya tidak seimbang. Dalam desain tersebut efisiensi siklus Brayton ideal sebesar $63.4 \%$, dan aktual sebesar $34.7 \%$. Selain itu, data kinerja dari desain MTG sebelumnya dapat dilihat pada Tabel 1. Desain pada Gambar 2 menggunakan desain MTG sentrifugal, sedangkan untuk desain pada penelitian ini menggunakan 
desain MTG tipe aksial, dimana perbedaan desainnya terletak pada posisi poros kompresor dan turbin serta pemanfaatan material dari MTG yang digunakan yaitu Stainless Steel 201. Pada desain MTG tipe aksial poros akan sejajar dengan kompresor dan turbin itu sendiri.

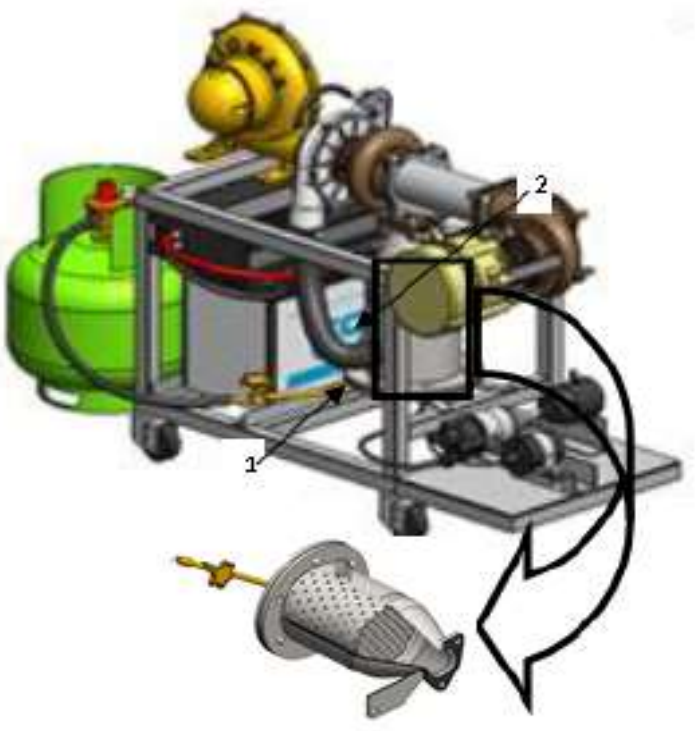

Gambar 5. Rancangan MTG Awal Tabel 1. Data MTG Desain Awal

\begin{tabular}{|c|c|c|}
\hline \multicolumn{2}{|c|}{ A. Kondisi Ideal } & \multirow{2}{*}{$\begin{array}{c}\text { Desain Mikroturbin Gas } \\
\text { Desain Turbin Gas } \\
\text { Sebelumnya }\end{array}$} \\
\hline No & Data Parameter & \\
\hline 1 & Suhu udara masuk kompresor & $36^{\circ} \mathrm{C}[309 \mathrm{~K}]$ \\
\hline 2 & $\begin{array}{lll}\text { Tekanan } & \text { atmosfer masuk } \\
\text { kompresor } & & \\
\end{array}$ & 1,01325 bar \\
\hline 3 & Suhu gas masuk turbin & $950^{\circ} \mathrm{C}[1223 \mathrm{~K}]$ \\
\hline 4 & Konstanta & 1,4 \\
\hline 5 & Perbandingan Tekanan $\left(r_{p}\right)$ & 11,1 \\
\hline 6 & Entalpi udara masuk kompresor & $309,24 \mathrm{~kJ} / \mathrm{kg}$ \\
\hline 7 & $\begin{array}{l}\text { Bilangan Prandtl udara masuk } \\
\text { kompresor } r\left(\mathrm{Pr}_{1}\right)\end{array}$ & 1,5374 \\
\hline 8 & Suhu udara keluar kompresor & $45^{\circ} \mathrm{C}[318 \mathrm{~K}]$ \\
\hline 9 & entalpi udara keluar kompresor & $317,78 \mathrm{~kJ} / \mathrm{kg}$ \\
\hline 10 & Kerja kompresor ideal $\left(\mathrm{W}_{\mathrm{k}}\right.$ ideal) & $8,544 \mathrm{~kJ} / \mathrm{kg}$ \\
\hline 11 & $\begin{array}{lll}\begin{array}{l}\text { Bilangan } \\
\text { kompresor }\end{array} & \text { Prandtl } & \text { keluar } \\
\end{array}$ & 1,7065 \\
\hline 12 & entalpi gas masuk turbin & $1304,853 \mathrm{~kJ} / \mathrm{kg}$ \\
\hline 13 & $\begin{array}{l}\text { Bilangan Prandtl gas masuk } \\
\text { turbin }\left(\mathrm{Pr}_{3}\right)\end{array}$ & 257,34 \\
\hline 14 & Panas ideal $\left(Q_{\text {in ideal }}\right)$ & $987,073 \mathrm{~kJ} / \mathrm{kg}$ \\
\hline 15 & $\begin{array}{llll}\text { Bilangan Prandtl gas keluar } \\
\text { turbin }\end{array}$ & 23,18 \\
\hline 16 & Suhu gas keluar turbin & $660,4 \mathrm{~K}$ \\
\hline 17 & Entalpi gas keluar turbin & $670,9 \mathrm{~kJ} / \mathrm{kg}$ \\
\hline 18 & Kerja turbin ideal $\left(\mathrm{W}_{\mathrm{T} \text { ideal }}\right)$ & $633,95 \mathrm{~kJ} / \mathrm{kg}$ \\
\hline 19 & Panas keluar turbin & $361,66 \mathrm{~kJ} / \mathrm{kg}$ \\
\hline 20 & Efisiensi thermal ideal & $63,4 \%$ \\
\hline 21 & Back Work Ratio (BWR) & $1,4 \%$ \\
\hline \multicolumn{2}{|c|}{ B. $\quad$ Kondisi Aktual } & Desain Mikroturbin Gas- \\
\hline No & Data Parameter & Mashuri \\
\hline 1 & Rasio perbandingan tekanan & 2,8 \\
\hline 2 & Suhu gas masuk turbin & $950^{\circ} \mathrm{C}[1223 \mathrm{~K}]$ \\
\hline 3 & $\begin{array}{l}\text { Aliran massa udara masuk } \\
\text { kompresor }\end{array}$ & $0,0233-0,18 \mathrm{~m}^{3} / \mathrm{s}$ \\
\hline 4 & Suhu udara masuk kompresor & $309 \mathrm{~K}$ \\
\hline 5 & Entalpi udara masuk kompresor & $309,236 \mathrm{~kJ} / \mathrm{kg}$ \\
\hline
\end{tabular}

\begin{tabular}{|c|l|c|}
\hline A. $\quad$ Kondisi Ideal & Desain Mikroturbin Gas \\
\hline 6 & $\begin{array}{l}\text { Bilangan Prandtl udara masuk } \\
\text { kompresor }\end{array}$ & 1,5374 \\
\hline 7 & Tekanan udara masuk kompresor & $1,01325 \mathrm{bar}$ \\
\hline 8 & Suhu udara keluar kompresor & $45^{\circ} \mathrm{C}[318 \mathrm{~K}]$ \\
\hline 9 & Tekanan udara keluar kompresor & $2,836 \mathrm{bar}$ \\
\hline 10 & Entalpi udara keluar kompresor & $318,282 \mathrm{~kJ} / \mathrm{kg}$ \\
\hline 11 & $\begin{array}{l}\text { Bilangan Prandtl udara keluar } \\
\text { kompresor }\end{array}$ & 1,669 \\
\hline 12 & Entalpi gas masuk turbin & $1304,853 \mathrm{~kJ} / \mathrm{kg}$ \\
\hline 13 & Suhu gas keluar turbin & $911,044 \mathrm{~K}$ \\
\hline 14 & Entalpi gas keluar turbin & $945,278 \mathrm{~kJ} / \mathrm{kg}$ \\
\hline 15 & Tekanan gas keluar turbin & $1,01325 \mathrm{bar}$ \\
\hline 16 & Efisiensi turbin & $97,9 \%$ \\
\hline 17 & Efisiensi isentropic kompresor & $98 \%$ \\
\hline 18 & Kerja aktual kompresor & $9,2 \mathrm{~kJ} / \mathrm{kg}$ \\
\hline 19 & Kerja aktual turbin & $352,024 \mathrm{~kJ} / \mathrm{kg}$ \\
\hline 20 & Tekanan aktual ruang bakar & $917,7 \mathrm{bar}$ \\
\hline 21 & Suhu gas aktual turbin & $952,829 \mathrm{~kJ} / \mathrm{kg}$ \\
\hline 22 & Entalpi gas aktual turbin & $986,233 \mathrm{~kJ} / \mathrm{kg}$ \\
\hline 23 & Panas aktual masuk ruang bakar & $342,8 \mathrm{~kJ} / \mathrm{kg}$ \\
\hline 24 & Kerja bersih & $2,6 \%$ \\
\hline 25 & Back Work Ratio (BWR) & \\
\hline 26 & Efisiensi thermal aktual siklus & \\
\hline & & \\
\hline
\end{tabular}
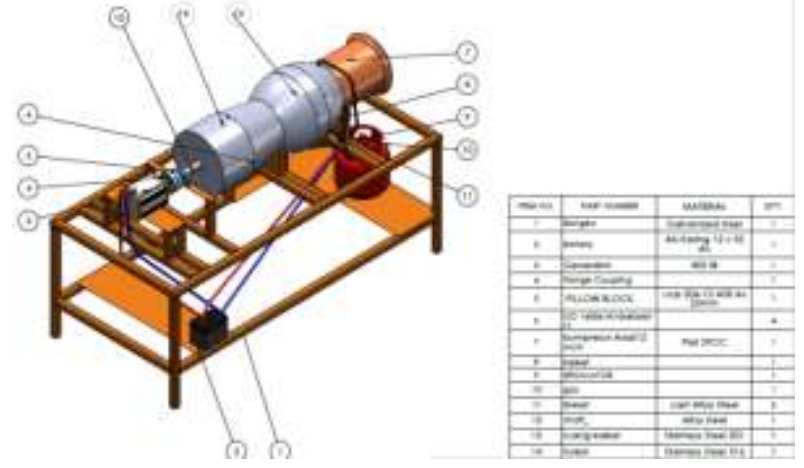

Gambar 6. Rancangan MTG Desain Baru

Gambar diatas merupakan desain rancangan Mikro Turbin Gas yang dibuat oleh tim, dimana perbedaan antara desain sebelumnya terletak pada sistem kerja yang dipakai menggunakan turbin aksial. Selain itu pada rancangan MTG saat ini tidak memakai turbocharge, adapun dimensi Mikro Turbin Gas saat ini adalah $2200 \mathrm{~mm}$ x $1000 \mathrm{~mm}$ x $1500 \mathrm{~mm}$. Mekanisme kinerja dari Mikro Turbin Gas adalah gas yang masuk ke dalam kompresor akan mengalami proses peningkatan tekanan. Saat operasi kompresor sentrifugal, mesin tersebut menarik udara dari lingkungan sekitarnya ke dalam mesin. Udara tersebut kemudian ditekan untuk meningkatkan tekanan dan suhunya. Diffuser kompresor kemudian meningkatkan tekanan statis udara dan menurunkan kecepatannya saat melewati jalur divergen (baling-baling) (Aditya 2014). Udara dengan kecepatan rendah bercampur dengan bahan bakar di ruang bakar (combustion chamber) dibutuhkan komposisi yang proporsional antara bahan bakar, udara, dan pemantik api agar 
api pada combustion chamber dapat membakar secara terus menerus untuk menghasilkan pembakaran dengan temperatur yang tinggi, bertekanan tinggi, dan berkecepatan tinggi. Setelahnya Turbin digerakkan oleh gas bersuhu tinggi dari proses pembakaran untuk menghasilkan tenaga poros mekanis untuk menggerakkan kompresor. Mikro Turbin Gas memiliki sebuah sistem yang terkonstruksi dengan baik, dimana sistem MGT tersebut dapat ditunjukkan pada Gambar 7.

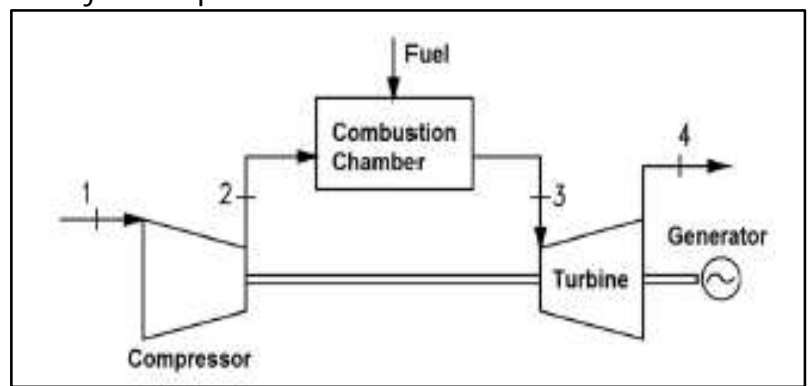

Gambar 7. Skema Mikro Turbin Gas

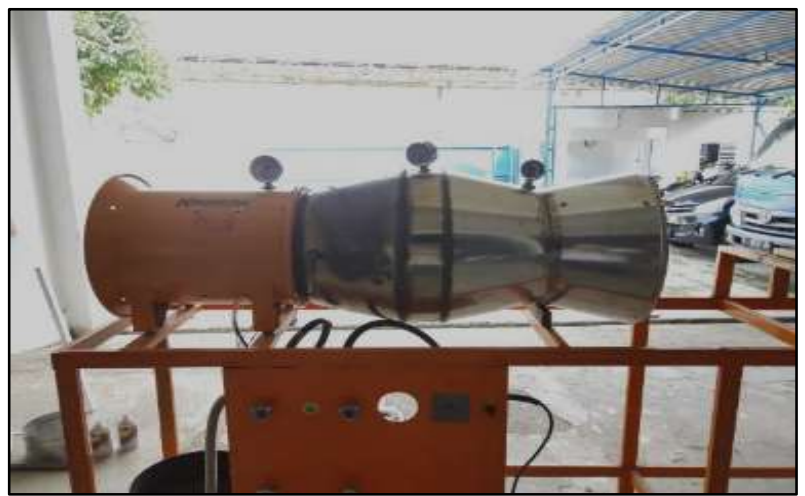

Gambar 8. Kondisi Awal Mikro Turbin Gas

Kondisi awal dari alat Mikro Turbin Gas yang dibuat ditunjukkan pada Gambar 8. Pada kondisi awal ini memakai impeller turbin bermaterialkan alumunium tuang. Setelah dilakukan pengujian alat secara langsung, didapatkan data berupa $T_{1}$, $T_{2}, T_{3}$, dan $T_{4}$ seperti pada Tabel 2, dimana $T_{1}$ merupakan suhu masuk kompresor, lalu $\mathrm{T}_{2}$ merupakan suhu masuk ruang bakar, $\mathrm{T}_{3}$ merupakan suhu masuk turbin dan $\mathrm{T}_{4}$ merupakan suhu keluar turbin.

Tabel 2. Hasil Uji Suhu Sebelum Modifikasi

\begin{tabular}{ccc}
\hline Parameter & Suhu $(\mathrm{K})$ & Entalpi $(\mathrm{kJ} / \mathrm{kg})$ \\
\hline $\mathrm{T}_{1}$ & 305,65 & 305,87 \\
$\mathrm{~T}_{2}$ & 306,45 & 306,67 \\
$\mathrm{~T}_{3}$ & $317,48 \mathrm{~K}$ & 317,75 \\
$\mathrm{~T}_{4}$ & $313,55 \mathrm{~K}$ & 313,81 \\
\hline
\end{tabular}

Apabila suhu masuk Turbin atau $T_{3}$ masih lebih tinggi dibandingkan dengan $T_{4}$ sehingga pada kondisi awal ini belum sesuai dengan siklus yang bekerja pada turbin yaitu siklus bryton, dimana jika pada siklus brayton seharusnya suhu keluar Turbin atau $T_{4}$ lebih tinggi dibandingan suhu masuk turbin atau $T_{3}$ karena jika suhu masuk turbin lebih besar dibandingkan suhu keluar turbin maka dapat disimpulkan bahwa alat Mikro Turbin Gas tersebut masih tidak maksimal secara kerjanya. Selanjutnya peneliti melakukan evaluasi pada bagian belakang turbin untuk diberikan penutup dan mengganti impeller turbin dengan menggunakan dua impeller bahan stainless steel agar massa dari impeller turbin dapat berkurang sehingga dapat menghasilkan kerja yang diharapkan (Gambar 9).

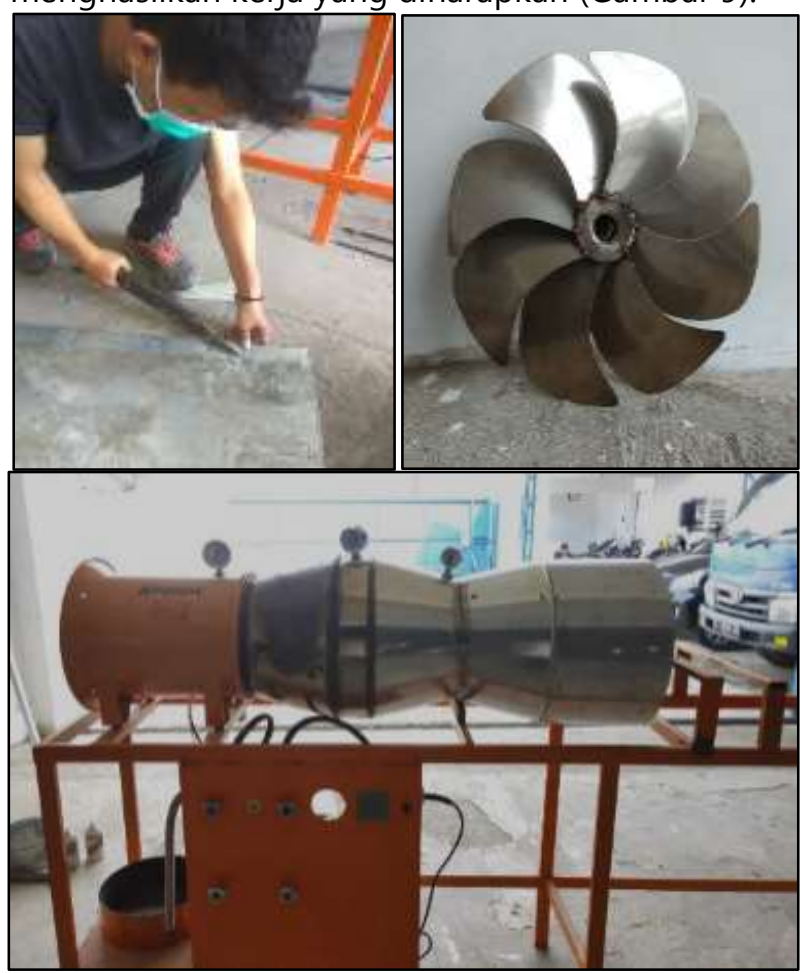

Gambar 9. Modifikasi MTG Tahap 1

Selanjutnya dilakukannya pengujian dan pengambilan data yang kedua, didapatkan data seperti pada Tabel 3 dibawah ini. Setelah itu dilakukan simulasi menggunakan ANSYS. Melihat nilai distribusi temperatur dan kecepatan yang berada pada diruang bakar seperti Gambar 10 dan 11 dimana nilai temperatur memiliki nilai paling tinggi sampai $766 \mathrm{~K}$ dan kecepatannya sebesar 3,4 $\mathrm{m} / \mathrm{s}$. 
Tabel 3. Hasil Uji Suhu Modifikasi 1

\begin{tabular}{|c|c|c|}
\hline Parameter & Suhu $\left({ }^{\circ} \mathrm{K}\right)$ & Entalpi $(\mathrm{kJ} / \mathrm{kg})$ \\
\hline $\mathrm{T}_{1}$ & 309,587 & 309,825 \\
\hline $\mathrm{T}_{2}$ & 310,187 & 310,433 \\
\hline $\mathrm{T}_{3}$ & 308,21 & 308,443 \\
\hline $\mathrm{T}_{4}$ & 333,354 & 333,721 \\
\hline
\end{tabular}

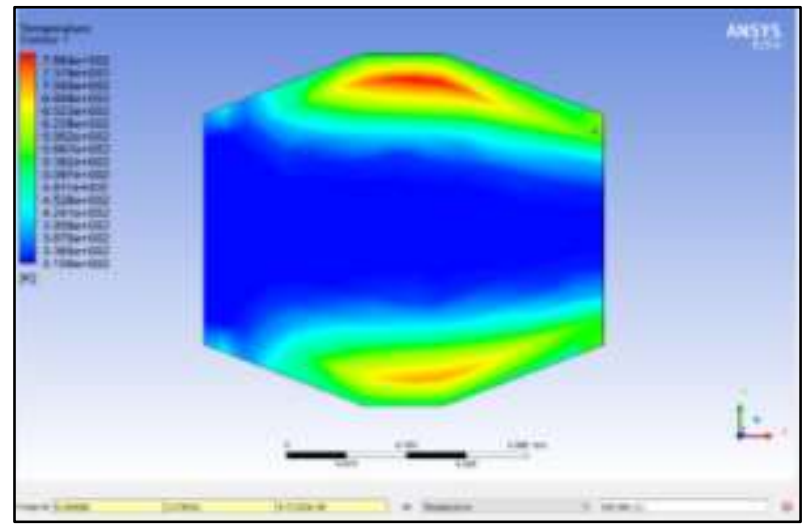

Gambar 10. Plot Temperatur Akhir Modifikasi 1

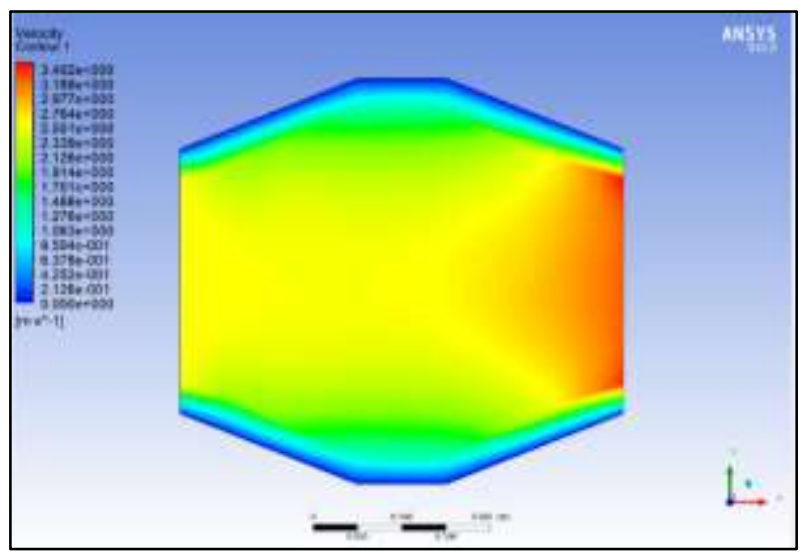

Gambar 11. Kecepatan di Dalam Ruang Bakar Modifikasi 1

Reaksi kimia yang terjadi diruang bakar adalah :

$\mathrm{C}_{3} \mathrm{H}_{8}+\mathrm{C}_{4} \mathrm{H}_{10}+11.5 \mathrm{O}_{2} \rightarrow 7 \mathrm{CO}_{2}+9 \mathrm{H}_{2} \mathrm{O}$

Pada reaksi ini menggunakan gas $L P G$ dengan kadar butane sebesar $50 \%$ dan propane sebesar $50 \%$, nilai mol untuk propane dan butane masing - masing 1 dan untuk oksigen sebesar 11,5 dengan hasil pembakarannya menjadi $7 \mathrm{~mol} \mathrm{CO}_{2}$ dan $9 \mathrm{~mol}$ $9 \mathrm{H}_{2} \mathrm{O}$. Sehingga untuk massa propana $\left(\mathrm{C}_{3} \mathrm{H}_{8}\right)$ dan butana $\left(\mathrm{C}_{4} \mathrm{H}_{10}\right)$ adalah 44 untuk massa relatif propane dan untuk butane sebesar 58 sehingga untuk inlet bahan bakar dari gas LPG sebesar 58 ditambah 44 sehingga menjadi $102 \mathrm{~kg} / \mathrm{mol}$ lalu untuk udara $\left(\mathrm{O}_{2}\right)$ sebesar 32 massa relatifnya dan karena untuk pembakaran membutuhkan $11,5 \mathrm{~mol}$ maka 11.5 dikalikan massa relatifnya 32 sehingga hasilnya $368 \mathrm{~kg} / \mathrm{mol}$. Sehingga untuk membakar $102 \mathrm{~kg}$ gas $L P G$ dibutuhkan $368 \mathrm{~kg}$ dalam simulasi CFD ini. Pengujian kinerja alat secara aktual dilakukan dan analisa simulasi dilakukan maka didapatkan pengujian secara aktual berbeda sangat jauh dengan analisa simulasi, oleh karena itu diperlukan modifikasi pada bagian ruang bakar karena suhu pada ruang bakar masih relatif rendah.

Selanjutnya dilakukan evaluasi pada bagian ruang bakar, maka peneliti mendapatkan bagian yang harus dimodifikasi yaitu pada bagian jumlah sumber api. Pada desain awal, alat Mikro Turbin Gas hanya memiliki 2 sumber api pada bagian kanan dan kiri, peneliti menyarankan untuk menambahkan 2 sumber api yaitu pada bagian atas dan bawah. Tujuan dengan penambahan 2 sumber api ini dapat membantu proses pembakaran sehingga suhu yang dihasilkan pada ruang bakar dapat meningkat. Proses yang dilakukan dalam penambahan 2 sumber api ini dengan melakukan pengeboran pada bagian atas dan bawah ruang bakar mikro turbin gas untuk aliran gas. Setelah itu dilakukannya pengelasan seperti pada Gambar 12 agar sumber api dapat menyatu dengan badan ruang bakar.

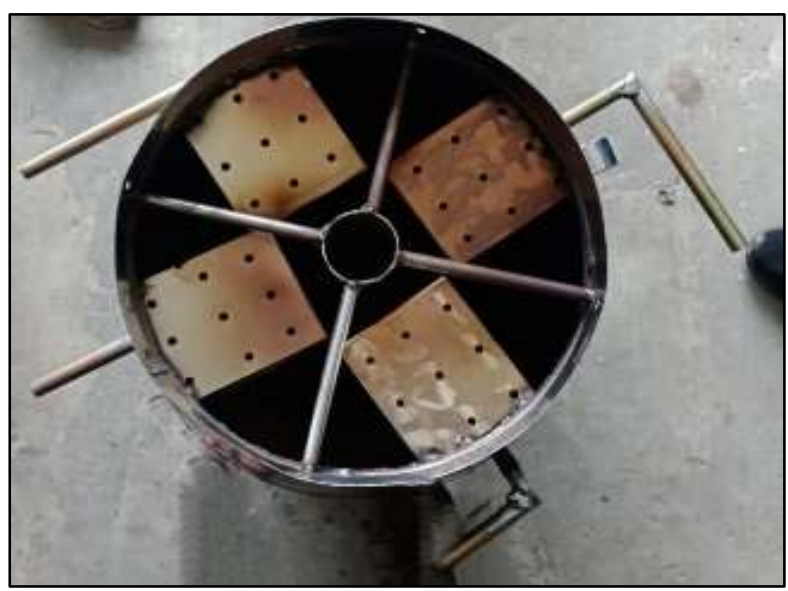

Gambar 12. Modifikasi MTG Tahap 2

Setelah modifikasi pada ruang bakar dilakukan, selanjutnya adalah pengambilan data kembali. Hasil yang didapatkan seperti pada Tabel 4. Pada tabel tersebut didapatkan suhu pada masuk turbin atau $T_{3}$ mengalami kenaikan sebesar 15 Kelvin. Maka didapatkan berupa kesimpulan dengan menambahkan 2 sumber api dapat mempengaruhi kinerja dari Mikro Turbin Gas walaupun tidak secara signifikan.

Tabel 4. Hasil Uji Suhu Modifikasi

\begin{tabular}{ccc}
\hline Parameter & Suhu & Entalpi $(\mathrm{kj} / \mathrm{kg})$ \\
\hline $\mathrm{T}_{1}$ & $305,65 \mathrm{~K}$ & 305,87 \\
$\mathrm{~T}_{2}$ & $306,65 \mathrm{~K}$ & 306,88 \\
$\mathrm{~T}_{3}$ & $323,75 \mathrm{~K}$ & 324,05 \\
$\mathrm{~T}_{4}$ & $318,25 \mathrm{~K}$ & 318,533 \\
\hline
\end{tabular}




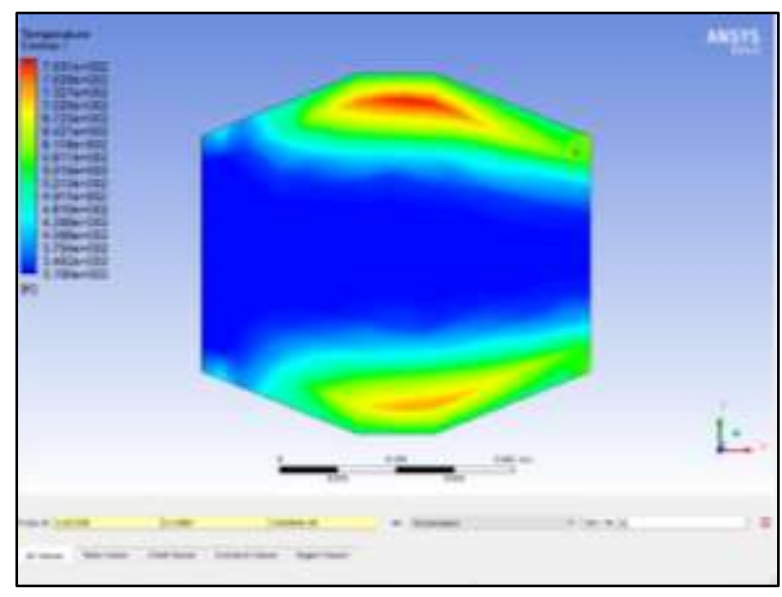

Gambar 13. Plot Temperatur Akhir Modifikasi 2

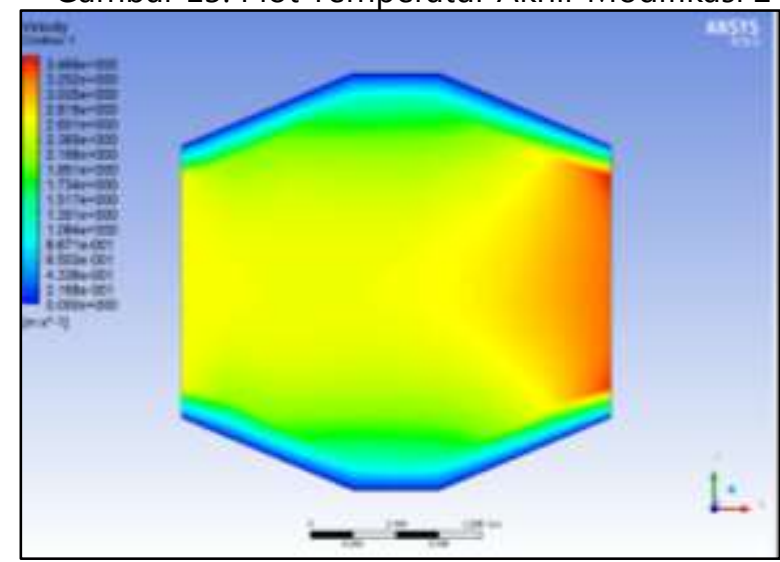

Gambar 14. Kecepatan di Dalam Ruang Bakar Modifikasi 2

Nilai distribusi temperatur dan kecepatan yang berada pada diruang bakar seperti Gambar 13 dan 14 dimana nilai temperatur memiliki nilai paling tinggi sampai $793 \mathrm{~K}$ dan kecepatannya sebesar 3,4 $\mathrm{m} / \mathrm{s}$. Pada simulasi ke 1 dan ke 2 memiliki nilai temperatur yang berbeda dengan simulasi dikarenakan nilai q $_{\text {in }}$ pada modifikasi ke 1 dan ke 2 memiliki perbedaan yang bisa dilihat pada Tabel 4. hal yang menyebabkan simulasi ANSYS yang ke 1 dan ke 2 berbeda dikarenakan nilai aliran masuk pada inlet bahan bakar berbeda karena nilai laju aliran massa bahan bakar akan berubah bila nilai qin nya juga berubah seperti yang dilihat pada tabel 4. Sehingga nilai massa aliran bahan bakar pada simulasi 1 adalah 0,0003 kg/s dan untuk simulasi 2 adalah $0,00047 \mathrm{~kg} / \mathrm{s}$, sehingga mengakibatkan perbedaan hasil dari simulasi ke 1 dan ke 2. Selanjutnya Tabel 6 merupakan perbandingan hasil perhitungan pada kondisi awal mikro turbin gas, modifikasi pertama, dan modifikasi kedua. Jika dilihat pada tabel diatas maka pada keadaan modifikasi kedua sudah mengalami perkembangan dibandingkan dengan kondisi awal maupun modifikasi pertama walaupun masih ada yang harus diperbaiki pada bagian kecepatan kompresor dengan menambahkan komponen berupa inventer.

Tabel 5. Perbandingan Entalpi Hasil Modifikasi 1 dan 2

\begin{tabular}{ccc}
\hline Parameter & Modifikasi 1 & Modifikasi 2 \\
\hline $\mathrm{h}_{1}$ & $305,87 \mathrm{~kJ} / \mathrm{kg}$ & $305,87 \mathrm{~kJ} / \mathrm{kg}$ \\
$\mathrm{h}_{2}$ & $306,67 \mathrm{~kJ} / \mathrm{kg}$ & $306,88 \mathrm{~kJ} / \mathrm{kg}$ \\
$\mathrm{h}_{3}$ & $317,75 \mathrm{~kJ} / \mathrm{kg}$ & $324,05 \mathrm{~kJ} / \mathrm{kg}$ \\
$\mathrm{h}_{4}$ & $313,81 \mathrm{~kJ} / \mathrm{kg}$ & $318,533 \mathrm{~kJ} / \mathrm{kg}$ \\
$\mathrm{q}_{\text {in }}$ & $11,08 \mathrm{kj} / \mathrm{kg}$ & $17,17 \mathrm{kj} / \mathrm{kg}$ \\
\hline
\end{tabular}

Tabel 6. Perbandingan Seluruh Parameter

\begin{tabular}{cccc}
\hline Parameter & Kondisi awal & Modifikasi 1 & Modifikasi 2 \\
\hline $\mathrm{T}_{1}$ & $309,587 \mathrm{~K}$ & $305,665 \mathrm{~K}$ & $305,65 \mathrm{~K}$ \\
$\mathrm{P}_{1}$ & $1,01325 \mathrm{bar}$ & $1,01325 \mathrm{bar}$ & $1,01325 \mathrm{bar}$ \\
$\mathrm{H}_{1}$ & 309,825 & $305,87 \mathrm{~kJ} / \mathrm{kg}$ & $305,87 \mathrm{~kJ} / \mathrm{kg}$ \\
$\mathrm{R}_{\mathrm{p}}$ & 0,992 & 1,068 & 1,106 \\
$\mathrm{Pr}_{1}$ & 1,55 & 1,48 & 1,48 \\
$\mathrm{~T}_{2}$ & $310,18 \mathrm{~K}$ & $306,45 \mathrm{~K}$ & $306,65 \mathrm{~K}$ \\
$\mathrm{H}_{2}$ & $310,43 \mathrm{~kJ} / \mathrm{kg}$ & $306,67 \mathrm{~kJ} / \mathrm{kg}$ & $306,88 \mathrm{~kJ} / \mathrm{kg}$ \\
$\mathrm{Pr}_{2}$ & 1,56 & 1,49 & 1,50 \\
$\mathrm{Wk}_{\mathrm{I}}$ & $0,825 \mathrm{~kJ} / \mathrm{kg}$ & $0,8 \mathrm{~kJ} / \mathrm{kg}$ & $1,01 \mathrm{~kJ} / \mathrm{kg}$ \\
$\mathrm{T}_{3}$ & $308,21 \mathrm{~K}$ & $317,48 \mathrm{~K}$ & $323,75 \mathrm{~K}$ \\
$\mathrm{H}_{3}$ & $308,44 \mathrm{~kJ} / \mathrm{kg}$ & $317,75 \mathrm{KkJ} / \mathrm{kg}$ & $324,05 \mathrm{~kJ} / \mathrm{kg}$ \\
$\mathrm{Pr}_{3}$ & 1,52 & 1,69 & 1,81 \\
$\mathrm{~T}_{4}$ & $333,35 \mathrm{~K}$ & $313,55 \mathrm{~K}$ & $318,25 \mathrm{~K}$ \\
$\mathrm{H}_{4}$ & $333,72 \mathrm{~kJ} / \mathrm{kg}$ & $313,81 \mathrm{~kJ} / \mathrm{kg}$ & $318,53 \mathrm{~kJ} / \mathrm{kg}$ \\
$\mathrm{Pr}_{4}$ & 2,006 & 1,62 & 1,70 \\
$\mathrm{Q}_{\text {in }}$ & $-1,99 \mathrm{~kJ} / \mathrm{kg}$ & $11,08 \mathrm{~kJ} / \mathrm{kg}$ & $17,17 \mathrm{~kJ} / \mathrm{kg}$ \\
$\mathrm{Q}_{\text {out }}$ & $23,525 \mathrm{~kJ} / \mathrm{kg}$ & $7,94 \mathrm{~kJ} / \mathrm{kg}$ & $12,66 \mathrm{~kJ} / \mathrm{kg}$ \\
Wturbin ideal & $-25,28 \mathrm{~kJ} / \mathrm{kg}$ & $3,94 \mathrm{~kJ} / \mathrm{kg}$ & $5,52 \mathrm{~kJ} / \mathrm{kg}$ \\
Efisiensi & $1.122,5 \%$ & $28,3 \%$ & $26.2 \%$ \\
Thermal Ideal & & & \\
BWR & $3,9 \%$ & $20,3 \%$ & $18,3 \%$ \\
\hline
\end{tabular}

\section{KESIMPULAN}

1. Kinerja mesin dapat dipengaruhi oleh beberapa faktor, diantaranya adalah dimensi mesin, kompresi, tekanan udara dan temperatur, dan proses dari pembakaran serta kualitas bahan bakar yang digunakan.

2. Peforma Mikro Turbin Gas dihasilkan masih relatif rendah, adapun faktor penyebabnya:

- Kecepatan putaran pada kompresor yang terlalu tinggi sehingga menyebabkan api pada ruang bakar sering mati ketika kompresor dinyalakan.

- Bagian ruang bakar pada alat Mikro Turbin Gas masih sangat sederhana, sehingga proses pemampatan udara dan bahan bakar tidak termampatkan dengan baik.

- Jarak antar sudu turbin yang masih terlalu renggang, sehingga hasil pembakaran tidak mampu memutarkan sudu secara maksimal. 
3. Setelah dilakukan pengujian simulasi dengan CFD ke 2 dan ke 3 didapatkan nilai temperatur sebesar $766 \mathrm{~K}$ dan kecepatan nya 3,4 m/s pada simulasi yang ke 2 dan untuk yang ke 3 nilai temperatur sebesar $793 \mathrm{~K}$ dan kecepatan nya $3,4 \mathrm{~m} / \mathrm{s}$. Dimana nilai $q_{\text {in }}$ berpengaruh terhadap nilai temperatur pada ruang bakar.

\section{DAFTAR PUSTAKA}

Aditya. 2014. Rancang Bangun Fuel Meter Untuk Mengukur Konsumsi Bahan Bakar Pada Mesin Diesel Isuzu C190. 01 (June) : 12-18.

Confidential, Ansys. 2015. Introduction to ANSYS Workbench Introduction to ANSYS Design Modeler.: 1-12.

Hermawan, Rudi et al. 2017. Analisa Perancangan Ruang Bakar Pada Pembangkit Listrik Mikro Turbin Gas Bahan Bakar Lpg. (November): 1-2.

Huicichea, A. (2011). Thermodynamic analysis of a trigeneration system consisting of a micro gas turbine and a double effect absorption chiller.

Koo, K. (2015). theoretical analysis on the effect of operation strategies on the environmental performance of micro turbine gas turbine trigeneration system in tropical region.

Kusnadi. (2016). rancangan mikro turbin gas berbahan bakar biogas untuk pembangkit listrik biomass 2,5 kW.
Nascimento. (2013). Micro Gas Turbine Engine : A review.

Oppong, Francis, Sybrand Johannes Van Der Spuy, and Abdullatif Lacina Diaby. 2015. "An Overview on the Performance Investigation and Improvement of Micro Gas Turbine Engine." $R$ \& $D$ Journal ofthe South African Institution ofMechanical Engineering (March): 35-41.

Pangestu, V. (2019). pendeteksi kebocoran gas LPG menggunakan sensor MQ - 2.

Patra, Sitakant. "- Design and Modeling of Axial Micro Gas Turbine II a Report Submitted in Partial Fulfillment of the - Design and Modeling of Axial Micro Gas Turbine II." Mechanical Engineering.

Raslavicius. (n.d.). Liquefied petroleum gas (LPG) as medium term option in the transition to sustainable fuels and transport.

Syukur, M. Hasan. 2011. "Penggunaan Liquified Petroleum Gases (LPG): Upaya Mengurangi Kecelakaan Akibat LPG." Forum Teknologi 01(2): 1-14. 